\title{
Şebekeden Bağımsız Hibrit Enerji Sistemleri Kullanılarak 40 Hanelik Bir Topluluğun Elektrik ve Termal Yük İhtiyacının Karşılanması: Teknik ve Ekonomik Analizleri
}

\author{
Sunay Türkdoğan ${ }^{1 *}$, Muhammet Talha Mercan², Tuğçe Çatal ${ }^{2}$ \\ 1 Yalova Üniversitesi, Mühendislik Fakültesi, Elektrik Elektronik Mühendisliği Bölümü, Yalova, Türkiye (ORCID: 0000-0002-9690-325X) \\ ${ }^{2}$ Yalova Üniversitesi, Mühendislik Fakültesi, Enerji Sistemleri Mühendisliği Bölümü, Yalova, Türkiye
}

(İlk Geliş Tarihi 11 Şubat 2020 ve Kabul Tarihi 9 Mart 2020)

(DOI: 10.31590/ejosat.688048)

\begin{abstract}
ATIF/REFERENCE: Türkdoğan, S., Mercan, M. T. \& Çatal, T. (2020). Şebekeden Bağımsız Hibrit Enerji Sistemleri Kullanılarak 40 Hanelik Bir Topluluğun Elektrik ve Termal Yük İhtiyacının Karşılanması: Teknik ve Ekonomik Analizleri. Avrupa Bilim ve Teknoloji Dergisi, (18), 476-485.
\end{abstract}

\section{$\ddot{O} \mathbf{z}$}

Bu çalışmada 40 haneli 160 kişiden oluşan bir topluluğun şebekeden bağımsız bir şekilde elektrik ve termal yük ihtiyacını karşılamak için çeşitli hibrit enerji sistemlerinin teknik ve ekonomik analizleri yapılmıştır. Ortalama $320 \mathrm{kWh} /$ gün elektrik ve 142,47 kWh/gün termal yük ihtiyaçlarının karşılanması ve bu amaç için kurulacak enerji sistemlerinin üreteceği enerjinin birim fiyatının gerçeğe yakın bulunabilmesi için HOMER (Hybrid Optimization Model for Electric Renewable) programı kullanılmıştır. Yapılan araştırmada ilk olarak Türkiye'nin ortalama güneș radyasyonu ve rüzgâr hızı değerlerine yakın parametrelere sahip Manisa'nın Gördes bölgesi seçilmiştir. İleriki aşamalarda ise tüm Türkiye coğrafyasına hitap edebilmesi ve en uygun sistemin belirlenebilmesi için çeşitli parametreler (dizel fiyatı, jeneratör çalışma yükü, jeneratör atık 1sı kullanımı, rüzgâr türbini kule yüksekliği, vb...) değiştirilerek hassasiyet analizleri yapılmıştır. Tüm bu çalışmalar sonunda şebekeden bağımsız şekilde tasarlanarak sistemlerden elde edilebilecek enerjinin birim maliyet fiyatının bölgeye göre değişiklik gösterdiği ve $\$ 0,151 / \mathrm{kWh}-\$ 0,198 / \mathrm{kWh}$ arasında değiştiği tespit edilmiştir. Şebekeden bağımsız sistem haricinde enerji nakil hatlarının uzatılması durumunda ilgili topluluğun enerji ihtiyacının karşılanması ve termal yük ihtiyacının elektrik enerjisiyle sağlanması gibi durumlar da incelenmiştir. Bu çalışma yenilenebilir enerji alanında kurulabilecek enerji sistemlerine iyi bir örnek teşkil edip özellikle ülke olarak bu alanda büyük bir potansiyele sahip olduğumuzu göstermekte ve diğer araştırmacıların da bu alanda çalışma yapmalarını teşvik edici özellikte olduğu düşünülmektedir.

\section{Meeting the Electrical and Thermal Load Demands of a 40- Household Community Using Off-Grid Hybrid Energy Systems: Technical and Economic Analysis}

\begin{abstract}
In this study, technical and economic analyses of various off-grid hybrid energy systems were investigated to meet the electric and thermal load demands of a group of 160 people within 40 household. HOMER (Hybrid Optimization Model for Electric Renewable) program has been utilized to meet the average $320 \mathrm{kWh}$ /day electricity and $142.47 \mathrm{kWh} /$ day thermal load requirements and to find the unit price of the energy generated by different hybrid energy systems. In the first study, the Gördes region of Manisa, which has
\end{abstract}

\footnotetext{
* Sorumlu Yazar: Yalova Üniversitesi, Mühendislik Fakültesi, Elektrik Elektronik Mühendilsiği Bölümü, Yalova, Türkiye, ORCID: 0000-0002-9690325X, sunay.turkdogan@yalova.edu.tr
} 
parameters close to the average solar radiation and wind speed values of Turkey, was selected. In the future stages, various parameters (diesel price, generator working load, generator waste heat usage, wind turbine tower height, and etc.) were modified and sensitivity analyses were made to figure the most appropriate system in different regions of TURKEY. At the end of all these studies, it was determined that the unit price of the energy varies by region and lies between $\$ 0.151 / \mathrm{kWh}-\$ 0.198 / \mathrm{kWh}$. The cases for grid extension and meeting the thermal energy needs by direct electricity were also examined. This study is a good example of the energy systems utilizing renewable energy and shows that we as an entire country have a great potential in this field and is thought to encourage other researchers to work in this world saving field.

Keywords: Hybrid Energy Systems, Renewable Energy, Energy Cost, HOMER.

\section{Giriş}

Enerji kaynakları yüzyıllardır insanlığın en önemli araştırma konularından biri olmuştur. İnsanların enerji kaynakların olan ilgisi ve ihtiyacı endüstri devriminden sonra artmış ve günümüze dek sürmüştür. Günümüzde enerji ihtiyacının büyük bir çoğunluğu fosil yakıtlar tarafından sağlanmaktadır. Geçmiş yıllarda fosil yakıtların ekonomik olarak uygunluğu, üretim sistemlerinin gelişmesi ve yaygınlaşması nedeniyle kullanımları en üst seviyede olmuştur. Kömürle başlayan fosil yakıt kullanımı daha sonra petrol ve doğal gaz' in da eklenmesiyle daha yaygın hale gelmiştir. Ancak, 20. yüzyılın sonlarına doğru çıkan petrol krizi bu kaynaklara olan güveni azaltmıştır. Ayrıca fosil yakıtların ömrünün azalması ve tükenecek olması ciddi bir problem açığa çıkarmıştır. Tüm bunlarla birlikte fosil yakıtların çevreyi olumsuz yönde etkilemesi, küresel ısınma ve çevre kirliliğine neden olması yeniilenebilir enerji kullanımını arttırmıştır. Yenilenebilir enerji kaynaklarının tükenme gibi bir probleminin olmaması, dünya üzerinde birçok yenilenebilir enerji kaynağının homojen olarak dağılması, yenilenebilir enerjiyi popüler hale getirmiştir [1].

Yenilenebilir enerji kaynaklarının hibrit bir sistem içinde bir arada kullanılması birçok açıdan olumlu özellikler barındırmaktadır. Güneş enerjisinin sadece gündüz saatlerinde olması, rüzgârın sürekli olmaması bu sistemlerin bağımsız kullanılmasını kısıtlamakta veya yüksek kapasitelerde kurulup depolama yapması sağlanarak enerji üretemediği durumlarda depolanan enerjinin kullanılması sağlanabilmektedir [2]. Yenilenebilir enerji sektörüne öncülük eden rüzgâr ve güneş enerjisinin hibrit enerji sistemlerinde birlikte kullanımı gün geçtikçe artmaktadır. Hibrit sistemlerde rüzgâr ve güneş enerjisinin yanında dizel jeneratör sisteminin kullanılması da enerjinin sürekli olmasını ve gereksiz kapasitede güneş veya rüzgâr enerjisi kurulumunu engeller ve enerji birim maliyet fiyatını düşürür [3].

Bu çalışmada 40 haneden oluşan 160 kişinin yaşadığı bir topluluğun hem elektrik ihtiyacının hem de termal yük ihtiyacının şebekeden bağımsız bir şekilde karşılanabileceği bir hibrit enerji sisteminin uygulanabilirliği araştırılmıştır. Meskenin elektrik yükü ve termal yük ihtiyaçları hesaplanmış ve seçilen bölgenin meteorolojik verileri kullanılarak HOMER programında hibrit enerji sistemi modeli oluşturulmuştur. Bu sistem, Türkiye'nin ortalama güneş radyasyonu ve rüzgâr hızı değerlerine yakın parametrelere sahip ve 21. yüzyıl Türkiyesinde çeşitli bürokratik süreçlerden kaynaklı şebeke bağlantısına ulaşamayan Manisa’nın Gördes bölgesinin verileri kullanılarak modellenmiştir. Hedef bölge haricinde aynı sistemin farklı bölgelerde uygulanabilirliğini tespit etme amacıyla güneş radyason değerlerini ve ortalama rüzgâr hızlarını değiştirerek uygulanabilirliği incelenmiştir. Oluşturulan sistemin maliyet analizleri yapıldıktan sonra sistemin optimize edilmesi için jeneratörün farklı çalışma yüklerinde devreye alınması, jeneratörün atık 1sısının kojenerasyon sistemiyle kullanılması, rüzgâr türbini gövde yüksekliğinin arttırılması, dizel fiyatının artması gibi parametreler kullanılarak hassasiyet analizleri yapılıştır. Termal yük kontrolörü ve batarya kullanımının sisteme hem ekonomik hem de teknik olarak etkileri araştırılmıştır. Tüm optimizasyonlar yapılıp hassasiyet analizleri incelendikten sonra maliyetin ne kadar düşürülebileceği yorumlanmıştır.

\section{Materyal ve Metot}

\subsection{Hibrit Sistem Girdileri}

\subsubsection{Proje Uygulama Yeri}

Projenin ilk uygulanma yeri Türkiye’de Ege bölgesinde bulunan Manisa ilinin Gördes (3856' N 28¹8' E) ilçesidir [4]. Araştırmalar 40 hane 160 kişiden oluşan bir topluluk için yapılmıştır.

\subsubsection{Elektrik ve Termal Yük Yapısı}

4 kişilik bir ailenin günlük ortalama elektrik tüketimi TEİAŞ tarafından yapılan araştırmada yaklaşık olarak 8 kWh olarak bulunmuştur [5]. 40 hanenin günlük $8 \mathrm{kWh}$ ’ten toplam günlük ihtiyacı $320 \mathrm{kWh}$ ’tir. Bir meskende elektrik tüketiminin akşam saatlerinde daha yüksek olması beklenmektedir. Bu çalışmada HOMER programında ön tanımlı olan topluluk yük profili kullanılmıştır (Şekil 1a). Topluluğun günlük elektrik tüketimi $320 \mathrm{kWh}$ olup gün içerisindeki tepe güç değerinin $38,62 \mathrm{~kW}$ olduğu gözlemlenmiştir (Şekil 1b).

Kurulacak olan sistem sadece elektrik yük ihtiyacını değil aynı zamanda meskenin termal yük ihtiyacını karşılayabilecek şekilde tasarlanmıştır. Bir evin ortalama 1sı kaybının metrekare başına $13 \mathrm{kWh}$ olduğu belirlenmiş [6] ve bir evin 100 metrekare olduğu varsayılarak bir evin yıllık 1sı kaybı $1300 \mathrm{kWh}$ olarak bulunmuştur. Toplulukta 40 hane olduğundan yıllık termal enerji ihtiyacının $52000 \mathrm{kWh}$ olduğu bulunmaktadır. Ancak meskenin 1Sı ihtiyacı elektrik yükü gibi sabit değil, yıl içerisinde mevsim koşullarına göre değiştiği bilinmektedir. Isı ihtiyacının büyük bir kısmının kış aylarında olduğu yaz aylarında ise 1sıtma ihtiyacı olmadığı için termal 
yük profili belirlenmiş ve Şekil 1c' deki gibi sisteme girilmiştir. Termal yük ihtiyacının \%24,13'ü Ocak, \%20,92'si Aralık, \%20,59'u Şubat, \%14,94'ü Mart, \%11,63 Kasım, \%5,8'i Nisan, \%1,98’i ise Ekim aylarında olduğu hesaplamıştır. Kalan aylarda 1sı kaybı olmadığı için termal yük ihtiyacı sıfır olarak kabul edilmiştir [7]. Sistemin yıl içerisindeki saatlik termal yük verileri Şekil 1c içerisinde verilmiştir.
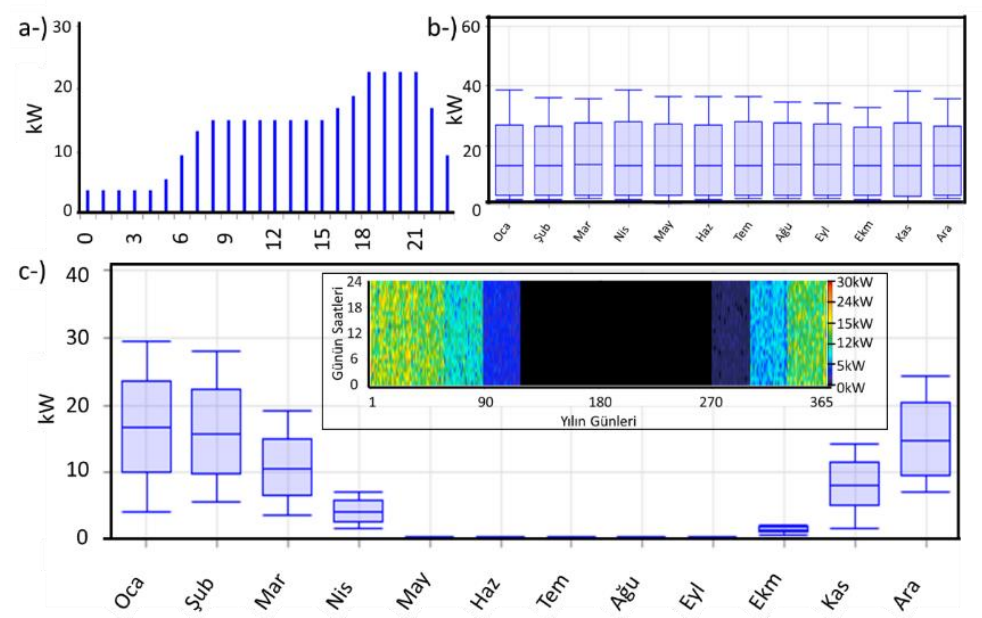

Şekil 1. Elekrik Tüketiminin (a) ün içerisinde saatlik, (b) aylık yük profilleri (c) aylık termal yük profili (İnset: yıllık termal yük profili)

\subsubsection{Bölgenin Güneş ve Rüzgâr Enerjisi Potasiyeli}

Güneş enerjisinden elektrik üretimi yapacak olan güneş panellerinin üretebileceği enerji miktarı bölgenin meteorolojik verileri ile doğru orantılıdır. Bölgenin solar enerji verileri HOMER programına entegre edilmiş olan NASA'nın veri tabanından alınmıştır. İlgili veriler Temmuz 1983-Temmuz 2005 yılları arasında 22 yıllık ölçümler sonucu elde edilmiş ve ortalaması alınarak belirlenmiştir [8]. Şekil 2' de görüldüğü gibi bölgenin solar enerji potansiyeli yaz aylarında fazlayken kış aylarında azalmakta ve yıl geneli ortalama günlük solar enerji potansiyeli $4,66 \mathrm{kWh} / \mathrm{m} 2$ olarak belirlenmiştir.

Rüzgâr türbinlerinin yatırım maliyetleri çok yüksek olduğundan kurulacak bölgenin rüzgâr hızı profili çok önemlidir. Bölgenin rüzgâr hızı profili yine NASA veritabanından alınmış ve ortalama $5,16 \mathrm{~m} / \mathrm{s}$ olduğu gözlemlenmiştir [8]. Veritabanındaki rüzgâr hızı verileri 50m yükseklikte 1983-1993 yılları arasında yapılan 10 yıllık ölçümlerin ortalamasıdır. Bölgenin rüzgâr hızı profili Şekil 2'de gösterilmiş ve kış aylarında solar enerjinin yetersiz kaldığı durumlarda rüzgâr enerjisinin tamamlayıcı enerji kaynağı olacağ 1 ve ikisinin beraber sinerjik etki göstereceği aşikârdır. Birbirini tamamlayıcı özellik göstermesinden dolayı da hibrit sistemlerde en çok kullanılan enerji kaynakları olmuşturlar.

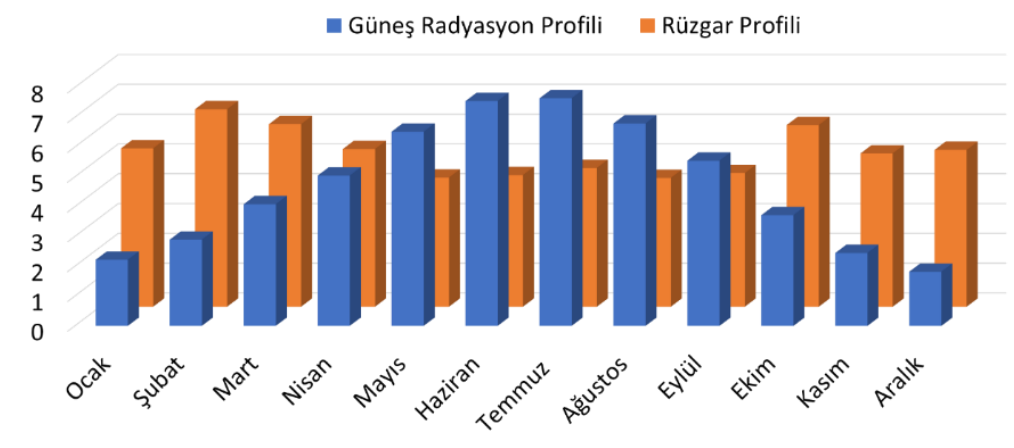

Şekil 2. Ayllk ortalama solar radyasyon $(\mathrm{kWh} / \mathrm{m} 2 / \mathrm{gün})$ ve rüzgâr hızl $(\mathrm{m} / \mathrm{s})$ profil verileri.

\subsection{Kullanılan Komponentler}

\subsubsection{Dizel Jeneratör}

Yapılan araştırmalara göre dizel jeneratörlerin $\mathrm{kW}$ başına 250\$-500\$ arasında bir maliyeti olduğu görülmüştür [3]. Bu projede kullanılan dizel jeneratör için $300 \$ / \mathrm{kW}$ maliyet değeri baz alınmıştır. Dizel jeneratörlerin fiyatı kapasitesi arttıkça ters orantılı olarak düşmektedir ve daha büyük kapasiteli jeneratörlerin kw başına maliyeti azalmaktadır. Hibrit enerji sisteminde kullanılan jeneratörün yakıt tüketimi ve verimlilik eğrileri Şekil 3a-b' te verilmiştir. Buradan görüldüğü gibi jeneratün etiket değerine yakın değerlerde kullanılması verimliliğin artmasına neden olmakta ve $\mathrm{kW}$ başına tüketilen yakıt miktarı azalmaktadır. Bu çalışmada dizel yakıtın fiyatı $1,2 \$$ alınmıştır [9].

\subsubsection{Rüzgâr Türbini}


Birim enerji maliyetinin düşürülmesi için en uygun sistemlerden biri rüzgâr türbini sistemidir. Ancak kurulum maliyeti yüksek olduğu için düşük kapasiteli rüzgâr santrali sistemleri fiyat bakımında elverişli değildir. Yapılan araştırmalarda rüzgâr türbini sisteminin kurulum maaliyeti $\mathrm{kW}$ başına 2500\$ [11] olduğu görülmüştür. Sistemde kullanılan rüzgâr türbini $10 \mathrm{~kW}$ güce sahip olup kurulum maliyeti 25000 'dır. Kurulum maliyetinin yanında değişim maliyeti $25000 \$$ ve bakım maliyeti $400 \$ / y 1$ olarak belirlenmiştir. İlgili rüzgâr türbine ait güç/hız eğrisi Şekil 3b’ de gösterilmiştir.

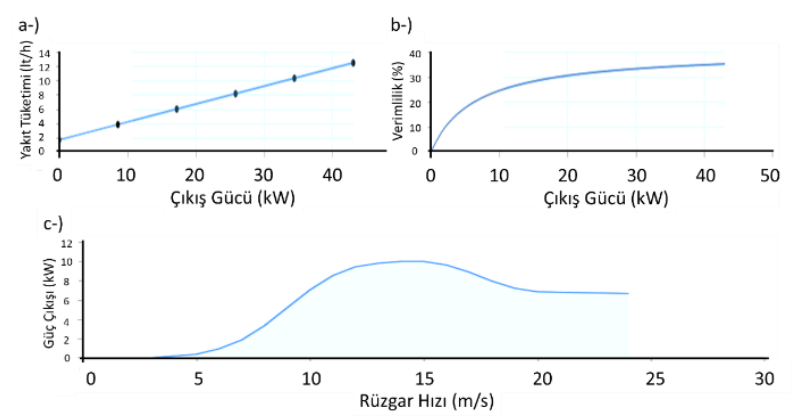

Şekil 3. Dizel jeneratöre ait a-) yakit tüketim ve b-) verimlilik eğrileri. c-) Rüzgâr tribününe ait güç-hız eğrisi.

\subsubsection{Güneş Paneli}

Güneş panelleri herhangi bir hareketli aksana gerek kalmadan güneş ışınlarından doğrudan elektrik enerjisi üretmeye yarar ve güneş enerjisi tüm dünyanın enerji ihtiyacını fazlasıyla karşılayabilecek en önemli yenilenebilir enerji kaynağıdır. Sistemde kullanılan panel HOMER programındaki entegre panellerden bir tanesi olup önemli olan parametre watt başına maliyet bilgisidir. Güneş paneli fiyatları günümüzde watt başına 45 cent [10], güneş paneli sistemlerinin kurulum maliyetleri ise $1000 \$ / \mathrm{kW}$ civarlarında olup yapılan hesaplamalarda da bu değerler baz alınmıştır [11].

\subsubsection{Batarya}

Bataryalar aldığı elektrik enerjisini kimyasal formda depolayabilen elektro kimyasal elemanlardır ve yenilenebilir enerji kaynaklarıyla üretilen enerjinin kullanım fazlasının daha sonra kullanılma amacı ile depolanmasını sağlar. Sistemde $1 \mathrm{kWh}$ kapasiteye sahip lityum iyon bataryalar kullanılmış olup maliyet değeriher $1 \mathrm{kWh}$ başına 200\$ olarak alınmıştır [12]. Kullanılacak olan batarya sayısı önemli oranda etkileyen deşarj derinliği yüzdesi ise $\% 80$ olarak alınmıştır.

\subsubsection{Termal Yük Kontrolörü}

Termal yük kontrolörü (Thermal Load Controller-TLC) termal yük sistemiyle elektrik yükü sistemi arasında bağlantı kurar. Elektrik sisteminde üretilen fazla enerjiyi termal yük barasına aktarır ve böylece ısınma amaçlı fazla enerji kullanımının önüne geçmiş olur. Termal yük kontrolörünün $\mathrm{kW}$ başına maliyeti HOMER programında verilen 200\$ esas alınarak hesaplama yapılmıştır.

\subsubsection{Kazan}

HOMER kazan (boiler) sistemini termal yükün ihtiyacını karşılamak için kullanır ve enerji kaynağı olarak dizel yakıt tüketilir. Sistemde kullanılan kazanın verimi \%85 olarak girilmiştir.

\subsection{Ekonomik Analiz Girdileri}

HOMER programı maliyet hesaplamaları yaparken yıllık gerçek faiz oranını kullanılır. Gerçek faiz oranı güncel faiz oranı ve enflasyon oranları kullanılarak bulunur. Yıllık gerçek faiz oranı aşağıdaki denklem ile bulunur:

$$
\mathrm{i}=\left(\mathrm{i}^{\prime}-\mathrm{f}\right) /(1+\mathrm{f}) \quad(1)
$$

burada, i yıllık gerçek faiz oranını, f yıllık enflasyon oranı, i' güncel faiz oranıdır. Bu çalışmada güncel faiz oranı $\% 12$ ve enflasyon oranı $\% 10,50$ olarak alınmıştır. Bu verilerden gerçek faiz oranının \%1,36 olduğu bulunmuştur [13].

\subsection{Hibrit Sistem Modeli}

Bu çalışmada Manisa'nın Gördes ilçesinde şebekeden bağımsız bir hibrit sistemin HOMER programı ile simülasyonları yapılmıştır. Yapılan simülasyonda en uygun sistemle birlikte diğer sistemlerin de enerji maliyeti ve net şimdiki maliyet değerleri bulunmuştur. Sonrasında ise ana sistem üzerinden hassasiyet analizleri ve optimizasyonlar yapılarak en uygun sistemin bulunması sağlanmıştır. Sistemde optimizasyon yapılırken dizel fiyatı, jeneratörün çalışma gücü aralıkları, jeneratörün kojenere sistem olarak kullanılması, sistem yüklerindeki değişimler, rüzgâr türbinin kule yüksekliği ve farklı bölgelerde sistemin karşılaştırılması için güneş radyasyon değerleri ve rüzgâr hızları değiştirilmiştir.. Tasarlanan hibrit sistemin şematik görünümü Şekil 4' teki gibi olup hem elektrik yük ihtiyacının hem de termal yük ihtiyacının karşılanmasını sağlayacak şekilde tasarlanmıştır. 


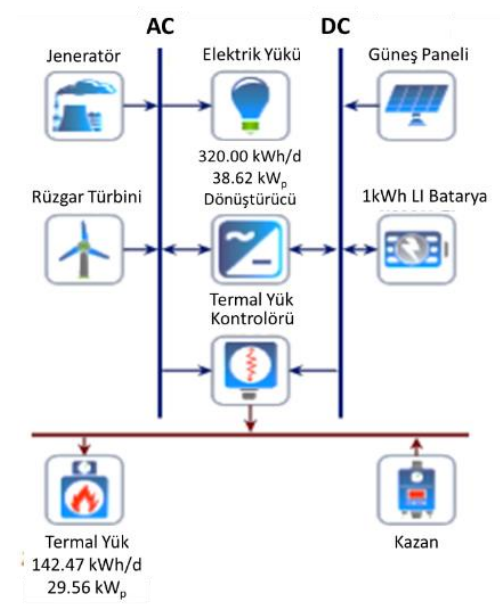

Şekil 4. Çalı̧̧mada kullanılan hibrit sistem modeli.

\section{3. Çalışma Sonuçları ve Tartışma}

Yapılan simülasyonlar neticesinde bölgeye kurulabilecek birçok sistem geliştirilmiştir. Tablo 1'de bulunan en uygun 8 sistemin sonuçları verilmiştir. Sonuçlar bulunurken bölgenin meteorolojik verileri kullanılmış, dizel fiyatı $1,2 \$$ alınmış, rüzgâr türbini yüksekliği $24 \mathrm{~m}$ kabul edilmiş, jeneratörün sadece elektrik üretimi yaptığı kabul edilmiş, jeneratörün devreye girme yükü \%25 olarak alınmış ve sistem yüklerinin değişmeyip sabit kaldığı durumlar incelenmiştir.

Tablo 1. Simülasyon sonucu açı̆̆a çıkan hibrit enerji modelleri listesi.

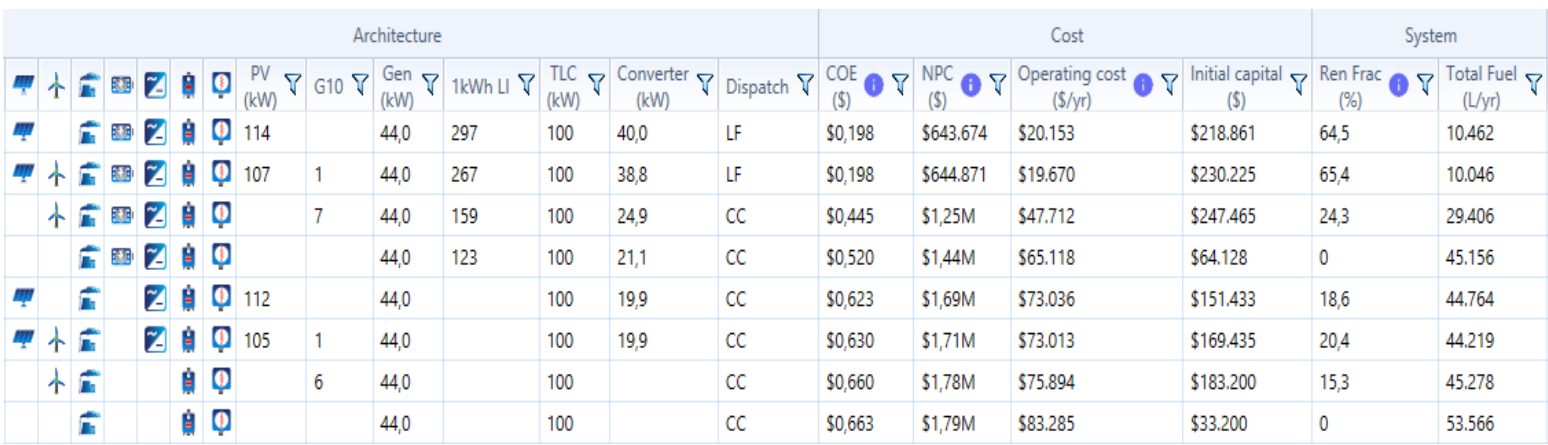

Simülasyon belirlenen parametreler dahilinde bölgedeki en uygun sistemlerinin analizini yapar. Yapılan simülasyonda en uygun birim enerji maliyeti 0,198 \$ olarak bulunmuş ve iki farklı sisteme ait aynı değer elde edilmiştir. Birinci sistem rüzgâr türbini kullanmazken ikinci sistem rüzgâr türbini kullanmaktadır. İlk sistemde 114 kW'lık güneş paneli, 44 kW'lık dizel jeneratör, 297 kWh'lik batarya depolama sitemi, $100 \mathrm{~kW}$ lık termal yük kontrolörü ve $40 \mathrm{~kW}$ 'lık dönüştürücü kullanılmıştır. İkinci sistemin tek farkı rüzgâr türbininin eklenmiş olmasıdır ve bu eklenme güneş panellerinin kurulum gücünü 107 kW'a, batarya sistemini 267 kWh'a düşürmüş ancak yenilenebilir enerji faktörünü \%64,5'ten \%65,4'e çıkarmıştır. Rüzgâr türbinin eklenmesiyle kışın güneş panellerinin üretemediği elektriği rüzgâr türbini üretmiş ve jeneratörün çalışma yükünü azaltarak yakıt tüketiminin 10462 lt' den 10046 lt' ye düşmesini sağlamıştır. Sistemin tek dezavantajı ise rüzgâr türbinin kurulum maliyetinin yüksek olması sebebiyle ilk yatırım maliyeti artmış olmasıdır. Buna karşın Tablo 2' de görüldüğü gibi emisyon değerlerinde \%3,98'lik azalma görülmüştür. Sistemin yatırım maliyetine yapılacak bir miktar eklemeyle kurulabilecek sistem çok daha çevreci olacak olup emisyon salınımlarını azaltacak ve aynı enerji maliyeti ile enerjinin üretilmesi sağlanacaktır. Sürdürülebilir bir dünya için bu ve bunun gibi eklemeler tüm sistemler için her daim düşünülmelidir.

Tablo 2. En uygun hibrit enerji sistemlerinin emisyon değerleri karşılaştırmast.

\begin{tabular}{|c|c|c|}
\hline & $\begin{array}{c}\text { 1. Sistem } \\
\text { (Birimler: kg/yıl) }\end{array}$ & $\begin{array}{c}\text { 2. Sistem } \\
\text { (Birimler: kg/yıl) }\end{array}$ \\
\hline Karbon Dioksit & 27.544 & 26.455 \\
\hline Karbon Monoksit & 79,5 & 73,4 \\
\hline $\begin{array}{c}\text { Yanmamış } \\
\text { Hidrokarbon }\end{array}$ & 3,47 & 3,2 \\
\hline Patikül Madde & 0,482 & 0,445 \\
\hline Sülfür Dioksit & 67,9 & 65,2 \\
\hline Nitröz Oksit & 74,7 & 69 \\
\hline
\end{tabular}

\subsection{Batarya Kullanılmasının Sisteme Etkileri}


Normal şartlarda batarya banklarının kullanılması sistem maliyetini önemli oranda arttıracağı düşünülerek tercih edilmezler. Ancak yapılan simülasyonlar sonucunda batarya kullanımın özellikle şebekeden bağımsız sistemlerde maliyete pozitif yönde etki ettiği görülmektedir. Güneş yoğunluğunun ve rüzgâr hızlarının yıl boyunca genele yayılmaması bataryasız sistemlerde jeneratörün kullanım sıklığını artırmaktadır. Batarya kullanılan sistemlerde birim enerji maliyeti 0,198\$’a kadar düşerken bataryasız sistemlerde birim enerji maliyetinin $0,623 \$$ olduğu Tablo 1 'de görülmektedir. Maliyetin yanı sıra bataryasız sistemlerin yenilenebilir enerjinin oranı $\% 64,5$ 'ten $\% 18,6$ 'a düşmüş ve beraberinde çevreye salınan zararlı gazların $\% 428,55$ oranında artmasına neden olmuştur. Alışılmışın aksine batarya depolama sisteminin hem maliyeti düşürdüğü hem de emisyon oranlarında ciddi düşüş̧e neden olduğu görülmüştür. Şekil 5 batayaların yıl içerisindeki şarj durumunu saatlik olarak göstermekte ve ne kadar aktif kullanım olduğu görülmektedir. Görüleceği gibi güneş ışınlarının yoğun olduğu öğle saatleri batarya bankları \%100 dolu olup günün diğer saatlerinde yüklerin beslenmesinde kullanılmaktadır.

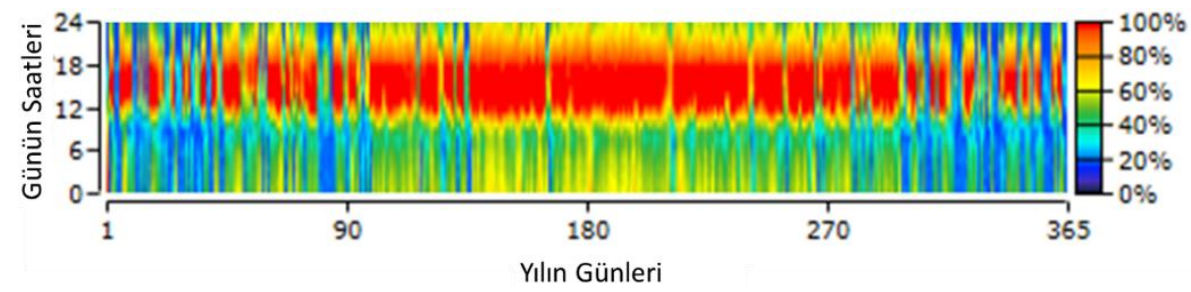

Şekil 5. Yll boyunca saatlik batarya banklarinin doluluk orant.

\subsection{Jeneratörün Farklı Çalışma Yüklerinin Sisteme Etkisi}

Yapılan simülasyonda hassasiyet analizi olarak jeneratörün devreye girme yükü $\% 25, \% 50, \% 75$ olarak 3 ayrı kategoride incelenmiş ve dizel fiyatının zamanla artarak $1,2 \$-1,3 \$-1,4 \$-1,5 \$$ değerlerinde olabileceği varsayılmıştır. Simülasyon sonucunda jeneratörün sadece $\% 75$ yükten fazla çalışması durumunda birim enerji maliyetinin $0,183 \$ / \mathrm{kWh}$ seviyelerine kadar indiği görülmüştür (tüm yüklerde kullanım halinde: $0,198 \$ / \mathrm{kWh}$ ). Ayrıca jeneratör sürekli yüksek yüklerde çalıştığı için çalışma verimi de sürekli yüksek seviyelerdedir. Jeneratörün yüksek verimlerde çalı̧̧ması daha az yakıt tüketmesini sağlamaktadır. Jeneratör tüm yüklerde devreye girdiğinde ortalama $12,9 \mathrm{~kW}$ gücünde çalışmışırı. Yıllık 4744 Litre yakıt harcayarak $12461 \mathrm{kWh}$ elektrik üretimi yapmıştır. Jeneratörün ortalama verimi ise $\% 26,7$ 'de kalmıştır. Ama jeneratör minimum $\% 75$ kapasitede ortalama $33 \mathrm{~kW}$ gücünde çalışarak \%33,7 verimlilik yakalamıştır. Yakaladığı bu verimlilikle hem yıllık 439 Litre daha az yakıt harcamış hem de $1795 \mathrm{kWh}$ daha fazla elektrik üretimi yapmıştır. Jeneratörün verimli kullanılması fazla elektrik üretimini de etkilemiştir. Verimli çalışma ile yaklaşı 4000 $\mathrm{kWh}$ daha az fazla elektrik üretilmiştir. Ayrıca çevreye yaymış olduğu zararlı gazların $\% 9,25$ oranında azaldığı görülmüştür. Dizel fiyatı $1,4 \$$ seviyesini geçtĭginde sisteme rüzgâr türbini eklenmesi gerektiğini ortaya çıkmıştır.

\subsection{Termal Yük Kontrolünün Sisteme Etkisi}

Termal yük kontrolörü sistemin ürettiği fazla elektriğin 9510 kWh’ lik kısmını geri kazandırarak termal yüke katkı sağlamış, böylece kazanın daha az üretim yapmasını sağlayarak çevreye salınan zararlı gaz emisyonunu \%16,73 oranında azaltmıştır. Sistemimizdeki ana güç üreticimiz fotovoltaik paneller olduğundan yaz aylarında daha fazla enerji üretilerek fazlalık enerjinin yaz aylarında birikmesine neden olmaktadır. Buna karşın termal yük ihtiyacımız kış aylarında yükselmekte ve bundan dolayı fotovoltaiklerin üretmiş olduğu fazlalık enerjinin termal yük kontrolörü tarafindan kullanılması özellikle yaz aylarında mümkün olmamaktadır. Şekil 6 yıl içerisinde üretilen fazlalık elektriğin ve termal yük ihtiyacını göstermektedir. Sistemin verimli kullanılabilmesi için özellikle Mayıs-Ekim ayları arasındaki üretilen fazlalık enerjinin farklı soğutma sistemlerinde kullanılması yaz aylarında soğutma için harcanan enerji miktarında önemli oranda azalmaya neden olur.

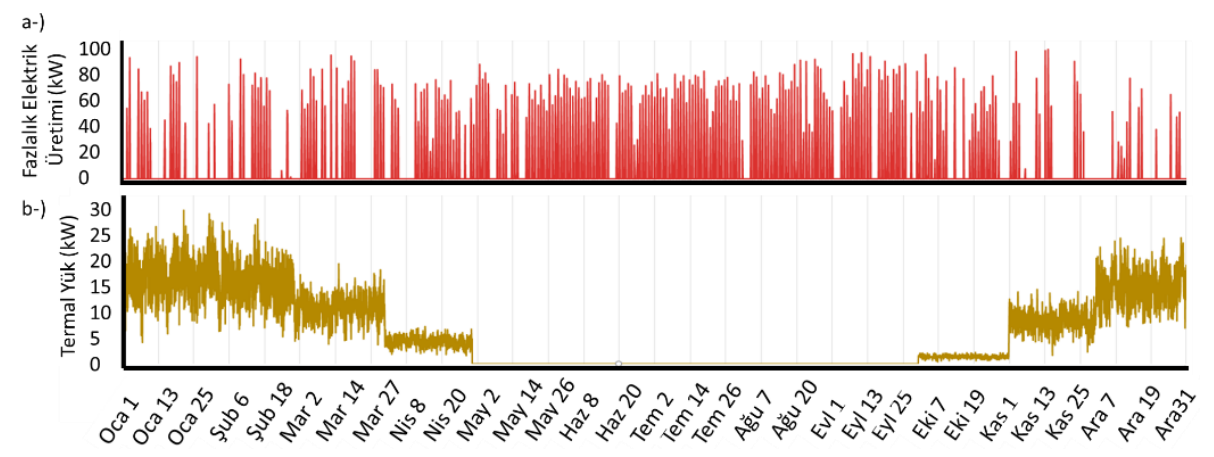

Şekil 6. Yıllık a-) fazla elektrik üretimi b-) termal yük profili grafikleri.

\subsection{Jeneratörün Kojenerasyon Sistemi İle Atık Isısının Kullanılması}

Jeneratörler elektrik üretimi yaparken kayıpların büyük kısmını 1sı kayıpları oluşturur. Bu 1sı kayıpları kojenerasyon sistemiyle 1S1 enerjisi olarak kullanılabilir. Kullanmış olduğumuz benzetim programı jeneratörün elektrik üretimi sırasında açığa çıkardığı 1sıyı termal yükte kullanmak üzere geri kazanabilir. Yapılan simülasyonda 1sı geri kazanım oranı \% 15 ' lere kadar arttrrıarak sisteme olan etkileri incelenmiştir. Jeneratörün ısı geri kazanım oranı arttıkça kazan yakıt tüketiminin yıllık 500 lt azaldığı görülmüştür. Tüketilen yakıt miktarındaki azalmanın yanı sıra $\mathrm{CO} 2$ ve $\mathrm{SO} 2$ emisyonlarında da \%4,4' e varan düşüşler gözlemlenmiş̧ir. Azalan yakıt 
tüketimiyle beraber birim enerji maliyeti de azalmış ve 0,191\$' a kadar düşmüştür. Jeneratör 1sı kazanım oranının birim enerjiye ve yakıt kullanımına etkisi Şekil 7a'da gösterilmiştir.

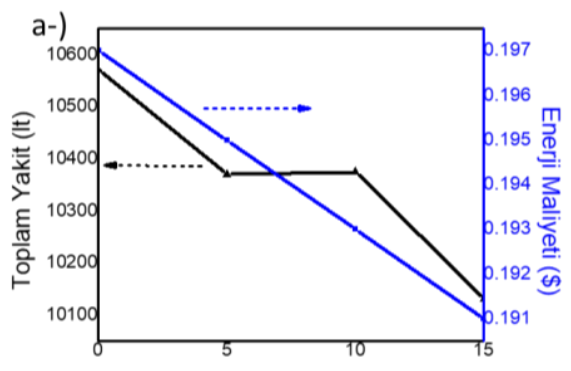

Isi Geri Kazanim Orani

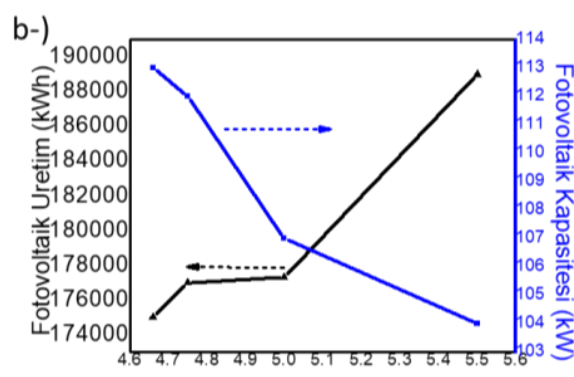

Ortalama Solar Radyasyon (kWh/m²/gün)

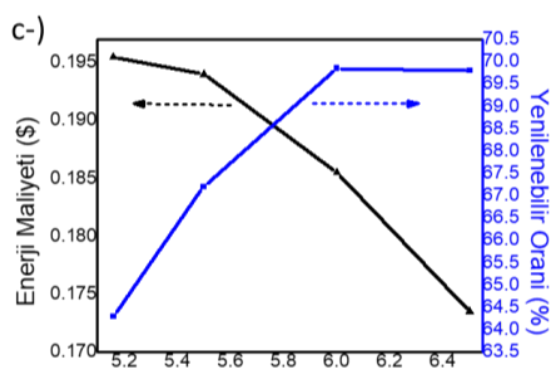

Ortalama Rüzgar Hizi $(\mathrm{m} / \mathrm{s})$

Şekil 7. a-)Jeneratör ısı kazanım oranının yakıt kullanımı ve birim enerji maliyetine etkisi. b-) Güneş radyasyonunun fotovoltaik enerji üretimine ve fotovoltaik kapasitesine etkisi c-) Ortalama rüzgâr hızının enerji maliyeti ve yenilenebilir enerji oranına etkisi.

\subsection{Lokasyona Bağlı Solar Radyasyonun Sisteme Etkisi}

Simülasyonu yapılan hibrit sistem daha önce de bahsedildiği gibi Türkiye'nin güneş ve rüzgâr olarak ortalama potansiyeline sahip bir bölgesinde yapılmıştır. Aynı sistemin solar radyasyon açısından daha iyi konumda olan bölgelerde kullanılması durumunda ekonomik ve teknik parametrelerde nelerin değişeceğini tespit etmek için ortalama solar radyasyon olarak 4,66-4,75-5 ve 5,5 kWh/m2 değerleri girilerek hassasiyet analizleri yapılmıştı. Yapılan simülasyonda günlük güneş radyasyon ortalaması arttıkça panellerin daha verimli çalıştığı, daha az panelle daha çok elektrik üretildiği ve birim enerji maliyetinin 0,179 \$'a kadar düştüğü Şekil $7 \mathrm{~b}$ 'de gösterilmiştir. Kış radyasyonun artması sonucunda termal yük kontrolörü kışın da fazla elektriği kullanabileceğinden termal yüke daha fazla katkı sağlayabilecektir. Bu sayede kazanın çalışması azalarak yakıt tüketimini düşecek ve emisyon değerlerinde azalma meydana gelecektir. Tüm bunların yanı sıra sistemin yenilenebilir enerji oranı da \%66,5' lere kadar çıkacaktır. Bu artış jeneratörün etkinliğinin azalıp güneş panelleri etkinliğinin arttığını ve bu sayede atmosfere salınan zararlı gazların azaldığını göstermektedir.

\subsection{Ortalama Rüzgâr Hızının Sisteme Etkisi}

Solar radyasyonda olduğu gibi simülasyonu yapılan sistemin daha fazla rüzgâr alan farklı bir bölgede kurulması durumunda sistem parametrelerinde meydana gelecek değişikliklerin tespiti için ortalama rüzgâr hızının 5,16-5,5-6 ve 6,5 m/s olması durumları incelenmiş̧ir. Ortalama rüzgâr hızının yaklaşık $5,2 \mathrm{~m} / \mathrm{s}$ 'nin üzere çıktığı zamanlarda rüzgâr türbinin aktif kullanımı birim enerji maliyetini düşürmektedir. Birim enerji maliyeti sabit kule yüksekliği ve sabit dizel fiyatında 0,174 \$'a kadar düşmüş ve yenilenebilir enerji üretim oranı \% $71,8^{\prime}$ e kadar çıkmıştı. Yenilebilir enerji oranının artması zararlı gazların salınımını \%10-15 oranında azaltımıştır. Rüzgâr hızı güneş radyasyonuna nazaran yıl boyunca daha orantılı olup rüzgâr türbinlerinden elde edilen enerjinin yıl boyunca çok fazla değişmemesini sağlamaktadır. Termal yük kontrolörü kış aylarında solar panelden alamadığı fazla elektrik enerjisini rüzgâr türbinlerinde almakta, bu da hem jeneratör elektrik üretiminin azalması hem de kazanın daha az termal enerji oluşturmasını önleyerek emisyon oranlarında ciddi düşüşlere neden olmaktadır. Ortalama rüzgâr hızının $6,5 \mathrm{~m} / \mathrm{s}$, kule yüksekliğinin ise 40 metreye çıkarılması birim enerji maliyetini 0,166 \$'a kadar düşürmüştür. Rüzgâr hızı ve kule yüksekliğinin sisteme etkisi ve enerji maliyetinin değişimi Şekil 7c’te gösterilmiştir.

\subsection{Termal Isı İhtiyacının Kazan Yerine Elektrikli Aletlerden Sağlanması}

Şimdiye kadar incelenen sistemlerde termal ısı ihtiyacının termal yük kontrolörü (fazlalık enerji) ve kazan tarafindan sağlandığ1 görülmüştür. Kazan sistemin karmaşık olması ve tüm evlere iletim hatlarının kurulması bazı sıkıntılar ortaya çıkarabileceğinden 1sıtma ihtiyacının toprak kaynaklı ısı pompaları ve normal elektrikli ısıtıcılar tarafından karşılanması durumları da incelenerek maliyet analizleri yapılmıştır. Isı pompaları rezistanslı ısıtıcılara göre 3 katı daha verimli olup rezistanslı 1sıtıcılar harcamış olduğu elektrik enerjisini doğrudan 1sı enerjisine dönüştürmektedir [14-15]. Isıtma için toprak kaynaklı 1sı pompası kullanıldığında ortalama 47,5 $\mathrm{kWh} /$ gün, geleneksel 1 sıtıcılar kullanıldığında ise $142,47 \mathrm{kWh} /$ gün enerjiye ihtiyaç duyulmaktadır. Şekil 8 termal yükün elektrik yükü olarak alınması sonucu ortaya çıkan hibrit enerji sistemi modelini göstermekte olup "Elektrik Yükü \#2" termal yükün elektrik enerjisi karşıllı̆ını ifade etmektedir.

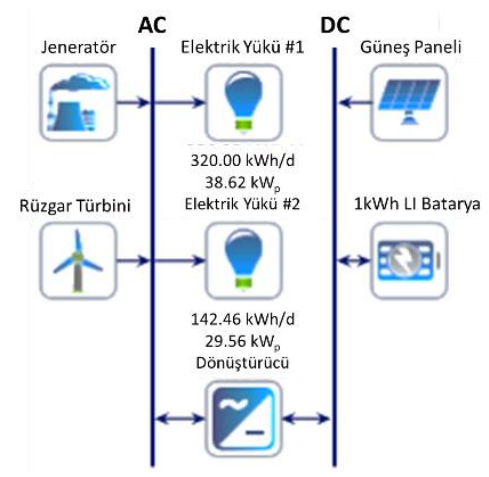

Şekil 8. Termal yükün elektrik enerjisinden karşılanması durumunda oluşturulan HOMER modeli. 
Yapılan simülasyonlar sonucunda 1sıtma ihtiyacının elektrik ile karşılanması durumunda sistemin kurulu gücünün 2 katı olması gerektiği görülmüştür. Toprak kaynaklı 1sı pompası kullanımında birim enerji maliyeti 0,218 iken geleneksel ssıtıcı kullanımında birim enerji maliyeti $0,248 \$$ olarak bulunmuştur. Toprak kaynaklı 1S1 pompası ve geleneksel 1sıtma sistemlerinin kullanılması durumunda sistem parametrelerinin ne olacağı Tablo 3' te görülmektedir. Toprak kaynaklı 1s1 pompası kullanımında geleneksel 1sıtıcılardan elde edilen sisteme göre kurulu güç $\% 25$ oranında azalmış ve depolama ihtiyacı $531 \mathrm{kWh}$ ' ten $380 \mathrm{kWh}$ 'e inmiştir. Toprak kaynaklı ısı pompası kullanımı enerji maliyetini ciddi oranda azaltmış, yenilenebilir enerji oranını \%89,6' lara çıkarmış ve kazanda üretilen enerjinin ortaya çıkardığı hava kirliliğinin de önüne geçilmiştir. Ancak toprak kaynaklı 1sı pompasının kullanımı her ne kadar iyimser gözükse de kazan kullanımında elde edilen enerji maliyeti seviyelerine inilememiş ve kazan sisteminin en uygun 1sitma sistemi olduğu gerçeğini ortaya koymuştur.

Tablo 3. Isı pompast ve geleneksel lsitma sistemlerinin kullanılmast ile elde edilen sistem verileri.

\begin{tabular}{|c|c|c|c|c|c|c|c|c|c|c|c|c|c|c|}
\hline \multirow{2}{*}{ 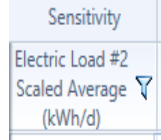 } & \multicolumn{8}{|c|}{ Architecture } & \multicolumn{4}{|c|}{ Cost } & \multicolumn{2}{|c|}{ System } \\
\hline & $1 \mathrm{P} \uparrow$ & ᄃ & ${ }_{(k W)^{P}}^{P V}$ & G10 7 & ${ }_{(\mathrm{kW})}^{\mathrm{Gen}} \mathrm{P}$ & $1 \mathrm{kWh} L \mathrm{P}$ & $\begin{array}{c}\text { Converter } \\
(\mathrm{kW})\end{array}$ & Dispatch $\nabla$ & ${ }_{(\$)}^{C O E} \odot \nabla$ & ${ }_{(S)}^{N P C} \rightarrow 7$ & $\begin{array}{c}\text { Operating cost } \\
(\$ / y r)\end{array}$ & $\begin{array}{c}\text { - Initial capital } \\
(\$)\end{array}$ & $\begin{array}{c}\text { Ren Frac } \\
(\%)\end{array}$ & $\begin{array}{c}\text { Total Fuel } \\
\text { (L/yr) }\end{array}$ \\
\hline 142 & 塄 & 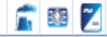 & 233 & & 75,0 & 531 & 50,6 & LF & $\$ 0,248$ & $\$ 883.710$ & $\$ 24.023$ & $\$ 377.306$ & 85,7 & 8.752 \\
\hline 47,5 & 罩 & - 8 & & & 75,0 & 380 & 43,5 & LF & $\$ 0,218$ & $\$ 615.258$ & $\$ 15.670$ & $\$ 284.928$ & 89,6 & 5.285 \\
\hline
\end{tabular}

\section{Tüm Optimizasyon ve Hassasiyet Analizlerinin Değerlendirilmesi}

Yapılan optimizasyon ve hassasiyet analizleri sonucunda sistemin daha da geliştirilebileceği açıkça ortaya konmuştur. Tüm araştırmalar sonunda maksimum verimlilikte çalışan sistemin şu özelliklere sahip olması gerektiği görülmüştür: Bataryaların etkin bir şekilde kullanılması, Jeneratörün en az \%75 kapasitede çalıştırılması, Jeneratörün atık 1sısından faydalanılması, Termal yük kontrolörünün (TLC) kullanılması, Kazan sistemi ile 1sıtma ihtiyacının karşılanması. Tüm bu parametreler sisteme eklendiğinde sistemin birim enerji maliyetinin $\$ 0,178$ seviyelerine düştüğü görülmüştür. Elektrik üretiminin büyük bir kısmı güneş panellerinden elde edilirken jeneratörün atık ısısından faydalanılması kazanın çalışmasını azaltmış ve emisyon salınımlarını düşürmüştür. Elektrik enerjisinin ve termal enerjinin sağlanmasında kullanılan üretim metotlarının dağılımı Şekil 9' da gösterilmiştir.
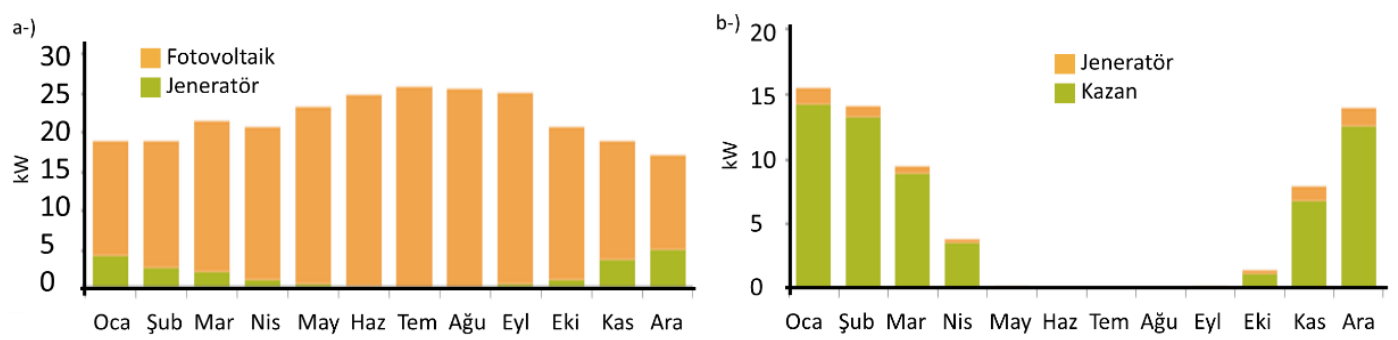

Şekil 9. Elektrik ve termal enerji üretiminin bileşenlere ayrılmış hali.

Sistemin elektrik gücünün \%92,4'lük bir kısmının güneş panelleri ile sağlanması jeneratörün yaz aylarında etkin kullanılmadığını göstermektedir. Yakıt tüketiminin çoğunluğu hem kazanın hem de jeneratörün etkisiyle kış aylarında olduğu görülmüştür. Yakıt tüketiminin yaklaşık \%46,4'ü jeneratör \% 53,6'sı kazan tarafından kullanılmaktadır. Yıllık yakıt tüketimi Şekil 10' da gösterilmiştir.
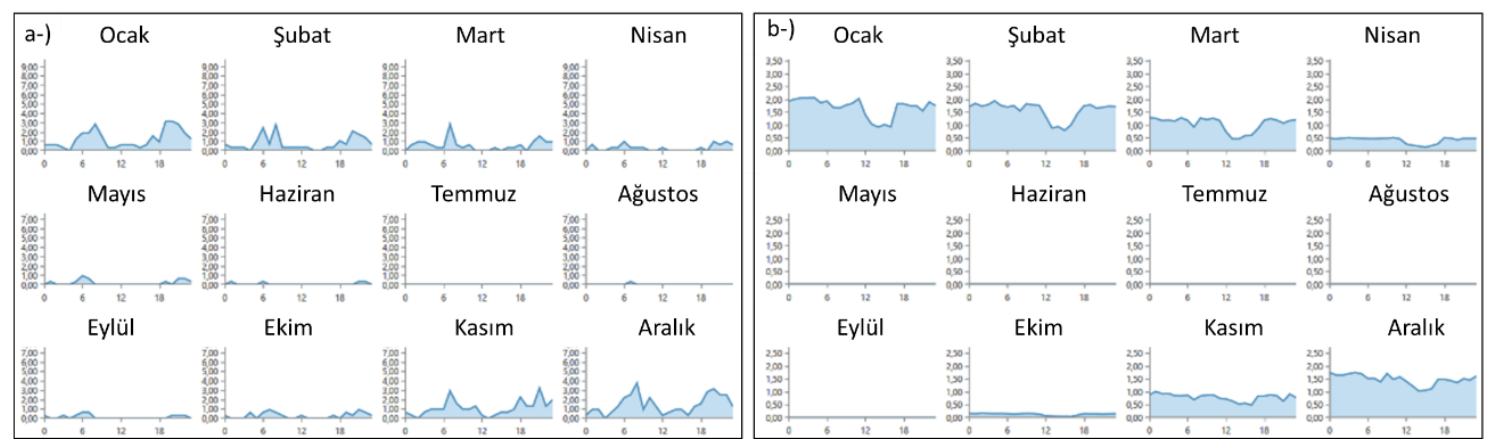

Şekil 10. Aylara göre anllk a-) Jeneratör ve b-) kazan yaktt kullanım oranları.

Yapılan araştırmalar Türkiye geneli ortalama güneş radyasyonu ve ortalama rüzgâr hızları için yapılmıştır. Ancak, Türkiye coğrafyasında ortalama rüzgâr hızının $6,5 \mathrm{~m} / \mathrm{s}$, ortalama güneş radyasyonun ise $5,5 \mathrm{kWh} / \mathrm{m} 2 /$ gün seviyelerine çıkabileceği konumlar söz konusu olabilmektedir [16,17]. Ortalama değer ile bahsedilen maksimum değerler arasında değișebilecek ortalama rüzgâr hızı ve ortalama solar radyasyon değelreriyle hassasiyet analizleri yapılmış ve Şekil 11' deki grafik elde edilmiştir. Türkiye'de rüzgâr hızının $6,5 \mathrm{~m} / \mathrm{s}$ hızlara ulaşabildiği yerlerde maliyetin rüzgâr türbinleri kullanılarak $\$ 0,166$ seviyesine indiği, güneş radyasyonunun 5,5 $\mathrm{kWh} / \mathrm{m} 2 /$ gün seviyelerine çıktığı bölgelerde ise enerji maliyetinin $\$ 0,164$ seviyelerine indiği görülmüştür. Şekil 11' de görüldüğü gibi rüzgâr hızı 5,5 m/s seviyesine ulaştı̆̆ında, sisteme rüzgâr türbini eklenmesi gerektiği görülmektedir. 


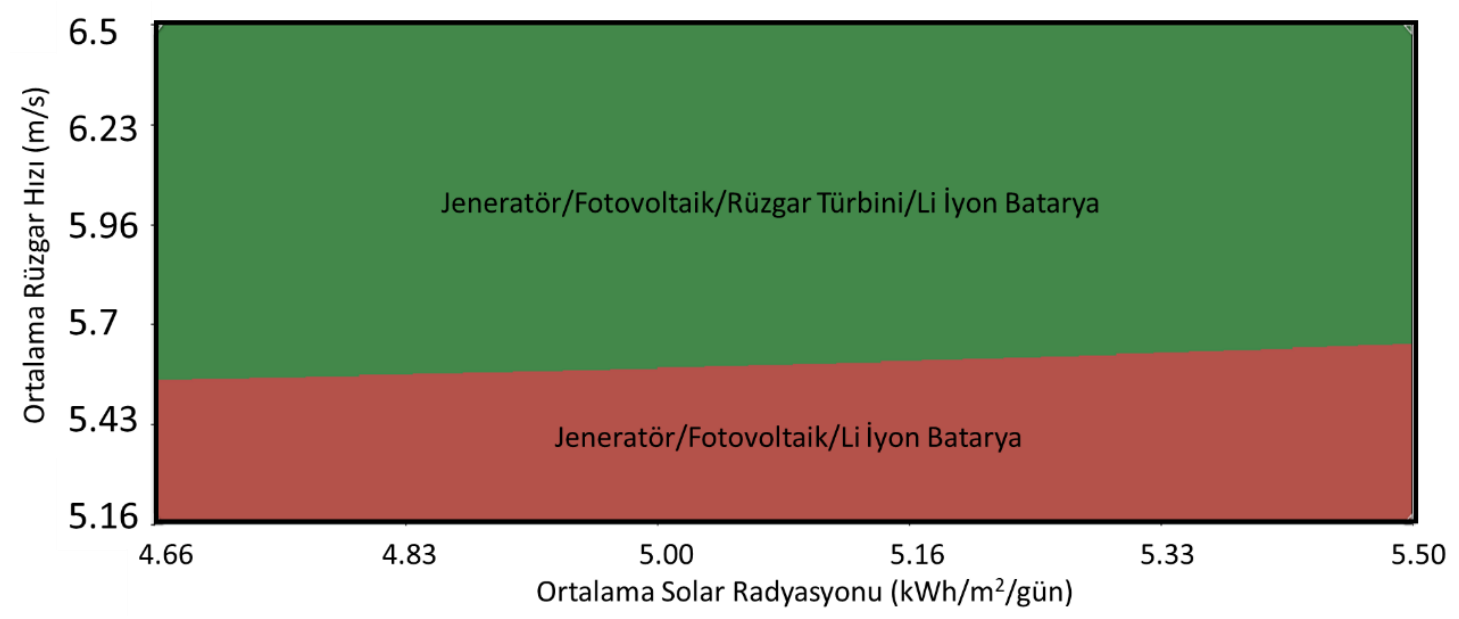

Şekil 11. Rüzgâr hızı ve güneş radyasyon değerlerine bağglı hassasiyet analiz sonucu.

Sistemin emisyon açısından değerlendirilmesi durumunda oldukça iyi sonuçların elde edildiği görülmektedir. Hem jeneratör hem de kazanda aktif olarak dizel yakıtı kullanmamıza rağmen yıllık CO2 salınımı 25447 kg/yıl olarak bulunmuştur. Bu değer tek başına çok gözükse de Türkiye' de şebeke elektrik üretimi için salınan CO2 miktarı $0,5 \mathrm{~kg} / \mathrm{kWh}$ civarlarındadır [19] ve hibrit enerji sisteminin $\mathrm{kWh}$ başına salınım değeri sadece $0,1 \mathrm{~kg}$ olup şebekeye nazaran 5 kat daha az zehirli gaz salınımı yapacağı ortaya çıkmaktadır.

Sistemin yatırım maliyetleri düşünüldüğ̈̈nde elektrik hatlarına kısa mesafeli konumlarda şebeke hatlarının uzatılarak elektrik enerjisi verilmesi sağlanabilir. Ancak, şebeke hatlarının km başına maliyeti ve gerekli yasal izin prosedürleri işleri zorlaştırmakta. Şebeke uzatma maliyeti ile sistem maliyeti karşılaştırıldığında 12,3 km2 lik mesafeye kadar şebeke hattının uzatılması, bu mesafeden sonra ise hibrit enerji sistemin kurulmasının daha mantıklı olacağı görülmektedir. Yapılan bu karşılaştırma sadece maliyet bazlı olup çevreye salınan zararlı gazlar kesinlikle düşünülmemiştir. Tüm bunlar düşünüldüğünde mesafe ne olursa olsun yenilenebilir enerji oranının yüksek olduğu sistemler sürdürülebilir bir dünya için en iyi seçenek olmalıdır.

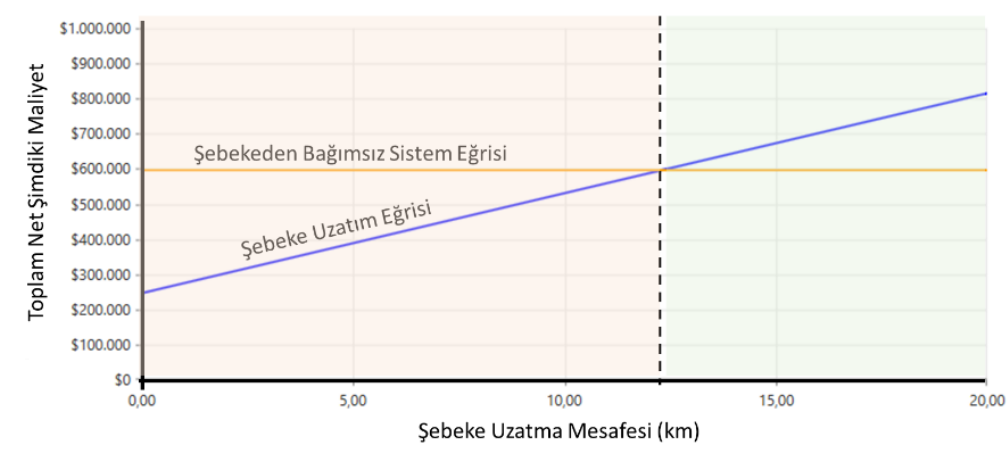

Şekil 12. Şebeke hattının uzatılması ve sistem maliyeti arasındaki iliş̧i grafiği.

\section{Sonuç}

$\mathrm{Bu}$ çalışmada elektrik hattının ulaşamadığı veya elektriğin verilemediği bölgeler için araştırmalar yapılarak şebekeden bağımsız şekilde hem elektrik hem de ısıtma yükünün karşılanabileceği hibrit sistem analizleri yapılmıştır. Toplanan verilerin HOMER programında kullanılmasıyla farklı sistemler karşılaştırılarak simülasyonlar yapılmıştır. Simülasyon sonuçlarına göre hibrit sistemde bataryaların etkin bir şekilde kullanılması gerektiği görülmüş, jeneratörün atık 1sısını kullanmanın sisteme katkıda bulunduğu açıkça gösterilmiştir. Yapılan araştırmalar sonucunda seçilen sistemin kurulum maliyeti $215.958 \$$, operasyon maliyeti $18.029 \$$ ve tüm projenin net bugün ki maliyeti 598.958\$ olduğu hesaplanmıştır. Birim enerji maliyetinin $\$ 0,164$ seviyelerine indiği görülmüştür. Maliyetin düşmesi toplu elektrik kullanımlarında bireysel yatııımlara göre daha iyi fiyat aralığına ulaşıldığını göstermiştir. Her hanenin yaklaşık 15000 \$ yatırım yapmasıyla 25 yıllık hem elektrik hem de ısıtma ihtiyacının karşılayabileceği düşünülmektedir. Günümüz şebeke maliyeti ortalama $0,116 \$ / \mathrm{kWh}$ seviyelerinde olup kurulacak sistemin 25 yıllık süre boyunca hem elektrik hem de ısıtma ihtiyacının ortalama $0,164 \$$ seviyelerine kadar inmesi bu alanda umut var olmamızı sağlamaktadır. Teknolojinin gelişmesiyle yenilenebilir enerji komponent maliyetlerinin düşmesi, fosil yakıtların tüketimine bağlı fiyat artışılla yakın zamanda hibrit enerji sistemlerinin ürettiği enerjinin birim maliyetinin geleneksel yolla üretilen enerjiden daha uygun olacağı gerçeğini ortaya koymaktadır.

\section{Kaynakça}

[1] Yılmaz, M. (2012). Türkiye'nin Enerji Potansiyeli Ve Yenilenebilir Enerji Kaynaklarının Elektrik Enerjisi Üretimi Açısından Önemi. Ankara Üniversitesi Çevrebilimleri Dergisi, 4(2), 33-54. 
[2] Engin, M. (2010). Bornova İçin Güneş-Rüzgâr Hibrid Enerji Üretim Sistemi Tasarımı. Celal Bayar Üniversitesi Soma Meslek Yüksekokulu Teknik Bilimler Dergisi, 2(13), 11-20.

[3] Türkdoğan, S., Dilber, S., \& Çam, B. (2018). Hibrit Enerji Sistemlerinin Şebekeden Bağımsız Bir Çiftlik Evinde Uygulanabilirliğinin Ekonomik Ve Teknik Açıdan İncelenmesi. Sinop Üniversitesi Fen Bilimleri Dergisi, 3(2), 52-65.

[4] Google Earth. (2020). Overview - Google Earth. [Online] Available At: Https://Earth.Google.Com/ [Accessed 11 Feb. 2020].

[5] Sayfa, A. And Bilgiler, F. (2020). Türkiye'de Hane Başına Düşen Ortalama Elektrik Tüketimi Ne Kadar ?. [Online] Gazelektrik. Available At: Https://Gazelektrik.Com/Faydali-Bilgiler/Elektrik-Tuketimi [Accessed 11 Feb. 2020].

[6] Passivhaus-Vauban.De. (2020). Pasifev Nedir?. [Online] Available At: Https://Www.Passivhaus-Vauban.De/Passivhaus.Tr.Html [Accessed 11 Feb. 2020].

[7] Eser, C., Öner, F., Başoğlu, O., Bilir, L., Özcan, N. Y., \& Özcan, H. G. Urla-İzmir'de Bulunan Müstakil Bir Ev İçin Bütünleşik Hibrit Sistem Analizi.

[8] Nasa, Surface Meteorology And Solar Energy, Https://Eosweb.Larc.Nasa.Gov/CgiBin/Sse/Grid.Cgi?\&Num=210131\&Lat=40\&Submit=Gnder\&Hgt=100\&Veg=17\&Sitelev=600\&Email=Skip@Larc.Nasa.Gov\&P $=$ Grid İd\&Step=2\&Lon=29, (26.12.2019).

[9] https://Www.Opet.Com.Tr/Manisa-Akaryakit-Fiyatlari [Accessed 22 Dec. 2019].

[10] Fu, R., Feldman, D. J., \& Margolis, R. M. (2018). Us Solar Photovoltaic System Cost Benchmark: Q1 2018 (No. Nrel/Tp-6a2072399). National Renewable Energy Lab.(Nrel), Golden, Co (United States).

[11] Erkoç, R. (2019). Güneş Enerji Santrallerinin Modellenmesi, Ekonomik Analizi Ve Değerlendirme: Almanya Ve Türkiye Uygulamaları (Master's Thesis, Fen Bilimleri Enstitüsü).

[12] Curry, C. (2017). Lithium-İon Battery Costs And Market. Bloomberg New Energy Finance, 5.

[13] Yılmaz, U., Demirören, A., \& Zeynelgil, H. L. (2010). Gökçeada'da Yenilenebilir Enerji Kaynakları İle Elektrik Enerjisi Üretim Potansiyelinin Araştırılması. Politeknik Dergisi, 13(3), 215-223.

[14] Energy, E. (2014). Guide To Pv Watts Derate Factors For Enphase Systems When Using Pv System Design Tools. An Enphase Energy Technical Report.

[15] Ozdemir, M. B., \& Ozkaya, M. G. (2015). Energy And Exergy Analyses Of The Vertical Type Ground-Sourced Heat Pump For Ankara Conditions. Journal Of Polytechnıc-Polıteknık Dergıs1, 18(4), 269-280.

[16] Mgm.Gov.Tr. (2020). Türkiye Rüzgâr Atlası - Meteoroloji Genel Müdürlüğü. [Online] Available At: Https://Www.Mgm.Gov.Tr/Genel/Ruzgar-Atlasi.Aspx [Accessed 27 Dec. 2019].

[17] Mgm.Gov.Tr. (2020). Radyasyon Mevsimler - Meteoroloji Genel Müdürlüğü. [Online] Available At: Https://Www.Mgm.Gov.Tr/Kurumici/Radyasyon_İller.Aspx [Accessed 27 Dec. 2019].

[18] Dulkadiroğlu, H. (2018). Türkiye'de Elektrik Üretiminin Sera Gazı Emisyonları Açısından İncelenmesi. Ömer Halisdemir Üniversitesi Mühendislik Bilimleri Dergisi, 7(1), 67-74. 